\title{
Organização da enfermagem brasileira
}

O presente artigo aborda a organização da enfermagem brasileira, desde sua origem, em 1923, até o ano de 2009 . Focaliza, sobretudo, as dimensões políticas, em articulação com suas entidades, em particular a ABEn, em diferentes conjunturas históricas, vivenciadas pelo país nesse período.

Descritores: Enfermagem; História da enfermagem; Participação.

\section{Organization of Brazilian nursing}

The present article discusses the organization of Brazilian nursing, from its origins in 1923 to the year of 2009. It focuses, above all, the political dimensions, in conjunction with its entities, particularly the ABEn, in different historical circumstances experienced throughout the country in that period.

Descriptors: Nursing; Nursing history; Engagement.

\section{Organización de la enfermería brasileña}

Este artículo aborda la organización de la enfermería brasileña, desde su creación en 1923 hasta el año 2009. Principalmente, se centra en las dimensiones políticas, en relación con sus entidades, en particular la ABEn, en diferentes momentos históricos que vivió el país en ese período.

Descriptores: Enfermería; Historia de la enfermería; Participación.

\section{INTRODUÇÃO}

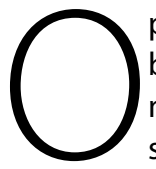

presente artigo trata da organização da enfermagem brasileira, destacando os períodos e os feitos de maior significado em sua história, empreendidos por suas entidades, mormente no tocante aos aspectos políticos.

Dessa forma, registra os passos iniciais em prol de sua organização, praticamente desde o nascimento, ainda na segunda década do século $X X$, na Escola de Enfermagem Ana Néri, no Rio de Janeiro. Sua vocação organizativa ficou evidenciada de imediato, logo após ter sido diplomada a primeira turma daquela escola em 1925. Nos meses subsequentes à formatura, as estudantes egressas do curso passaram a se reunir com o propósito de fundar uma associação de ex-alunas. No entanto, naquela ocasião, a ideia inicialmente discutida acabou se ampliando para a criação de uma associação que congregasse enfermeiros de todo o Brasil. Estávamos convictas de que ela se expandiria para todas as regiões brasileiras como de fato ocorreu.

Assim, em agosto de 1926 fundou-se a Associação Nacional de Enfermeiras Diplomadas, elegendo uma diretoria provisória, cuja presidência ficou a cargo da enfermeira Rimídia Bandeira de Souza Gayoso. Um ano mais tarde, essa diretoria seria substituída por outra definitiva, quando assumiu a presidência Edith de Magalhães Fraenkel. Contou, à época, com todo o apoio do Serviço de Enfermeiras do Departamento Nacional de Saúde Pública (DNSP), na pessoa de sua superintendente, a enfermeira norteamericana Ethel Parsons.

Logo nos primeiros anos, ainda em 1929, a mencionada associação filiou-se ao Conselho Internacional de Enfermeiras (ICN) e, depois, a outros organismos internacionais.

A entidade recebeu, posteriormente, novas denominações até 1954. Naquele ano, por ocasião do VII Congresso Nacional de Enfermagem, realizado em São Paulo, passa a se designar
Associação Brasileira de Enfermagem (ABEn). De agora em diante, assim será tratada neste texto mesmo quando nos referirmos a períodos anteriores da história ${ }^{(1)}$.

Em seu percurso, a ABEn, por muitas décadas, representou o principal e quase que exclusivo espaço de organização dos enfermeiros. Todas as lutas e reivindicações dos profissionais à época, incluindo as questões internas como crescimento, desenvolvimento e reconhecimento da profissão, passavam pela associação.

No transcorrer de sua trajetória, a entidade guardou uma forte vinculação com as escolas de enfermagem. Ela nasceu em uma escola, a Ana Néri, e se expandiu graças ao apoio das novas escolas, que foram sendo gradativamente criadas nas diversas regiões do país, notadamente a partir da década de 1940. Assim, todas as seções estaduais da ABEn contaram com o suporte de alguma escola de enfermagem para sua instalação e até mesmo manutenção. Torna-se importante registrar essa observação porque mostra a estreita relação entre o principal órgão representativo da categoria e a educação. Ainda na década de 1930, uma das primeiras iniciativas da ABEn foi a criação de uma revista, Anais de Enfermagem com o intuito de garantir uma melhor comunicação entre os associados. Para a realização desse intento, teve o respaldo irrestrito das diretoras das escolas de enfermagem, sobretudo com o trabalho dos professores, seus principais articulistas. Esse periódico, posteriormente, na década de 1950, passa a denominar-se Revista Brasileira de Enfermagem, a atual REBEn ${ }^{(1)}$.

Como veículo de comunicação, teve e continua desempenhando um papel importante na organização política da enfermagem brasileira, bem como no desenvolvimento acadêmico e técnico/científico da profissão.

Com esse mesmo propósito foram de grande significação a criação da Semana da Enfermagem, por iniciativa da Escola 
Ana Néri, no ano de 1940 e, na mesma década, a realização do primeiro Congresso Brasileiro de Enfermagem, em 1947, sob a coordenação da Associação.

Dentre seus inúmeros e reconhecidos feitos, a $A B E n$ trabalhou sempre em parceria com as escolas de enfermagem e cursos de auxiliar de enfermagem - estes últimos estruturados a partir da década de 1930, contando com a efetiva participação da professora Laís Netto dos Reys. Com o objetivo de acompanhar a formação dos profissionais, a ABEn influenciou e, ao mesmo tempo, foi sendo influenciada pelo contexto educacional de cada momento histórico. É oportuno ressaltar que tanto as escolas quanto a ABEn pautaram-se em uma linha bastante conservadora por muitas décadas. Persistiu assim mesmo quando a conjuntura nacional favorecia o debate de ideias progressistas, a exemplo do rico período de politização possibilitado pela organização dos inúmeros movimentos políticos/sociais, e outros fóruns de debate que antecederam o golpe civil-militar de 1964, que implantou um regime ditatorial que duraria 21 anos (1964-1985).

Porém, no que tange as reivindicações internas da profissão, a Associação sempre esteve vigilante e, nesse sentido, foi combativa e atuante junto aos órgãos governamentais na busca da defesa de interesses da categoria. Nesse sentido, lutou de modo intransigente pela regulação do exercício profissional, tendo sido afinal contemplada com a aprovação da Lei $n^{\circ}$ 2.604 de 17/09/1955, da Presidência da República. Da mesma forma, empenhou-se na luta pela inclusão do enfermeiro no nível técnico/científico, conseguindo, por força da Lei no 3.780/60, a sua equiparação aos demais profissionais liberais ${ }^{(2)}$.

Vale ressaltar que todas essas lutas empreendidas pela $A B E n$ em função da organização e crescimento da profissão como a manutenção da revista - em alguns momentos com extrema dificuldade financeira -, a aprovação da lei que regulamentou o ensino de enfermagem no país (Lei no 775/49), e a observação criteriosa para a abertura de escolas de enfermagem foram fundamentais para a afirmação e o reconhecimento da enfermagem. E um destaque importante nessas primeiras décadas deve ser dado ao Levantamento sobre os Recursos e Necessidades de Enfermagem no País, realizado no período 1956-1958, considerado um dos documentos mais significativos produzidos pela $A B E n$, principalmente em virtude das dificuldades de comunicação da época. Tinha como objetivo central "contribuir para o desenvolvimento da enfermagem no Brasil", partindo, naturalmente, de um mapeamento quantitativo das escolas e de profissionais, do nível de capacitação e das condições de trabalho da enfermagem brasileira, identificando a situação de cada região, com suas dificuldades e possibilidades. Para isso, a ABEn reivindicou e conseguiu apoio e participação de vários ministérios, escolas de enfermagem e cursos de auxiliares de enfermagem, secretarias de saúde, CAPES e IBGE, além de outros colaboradores. Contou para tal empreendimento com a ajuda financeira da Fundação Rockefeller(2).

O relatório deste estudo não somente identificou problemas inerentes à profissão, tanto no campo da formação quanto do exercício profissional, resultando em inúmeras recomendações, mas apontou igualmente para questões gerais da área da saúde. Esses dados serviram de parâmetro para uma análise das próprias condições de vida e saúde da população brasileira e da situação real dos profissionais no exercício de suas funções no Brasil. Com o êxito alcançado, foi formada uma Comissão de Seguimento do Levantamento, assim intitulada, com o objetivo de dar continuidade ao trabalho iniciado, mantendo a Associação sempre atualizada em torno de dados essenciais à formação e ao exercício profissional. A falta de recursos financeiros inviabilizou o trabalho da comissão, que se manteve ativa por apenas três ou quatro anos. Contudo, internamente a Associação criou a comissão de documentação e estudos da ABEn que, por longos anos, passou a informar acerca de dados relacionados ao ensino(1).

\section{A ética como meta}

Outra luta empreendida pela ABEn, com inúmeras dificuldades, diz respeito à criação do Conselho de seus profissionais. A entrada do primeiro anteprojeto na Divisão de Organização Sanitária (DOS), do Ministério da Educação e Saúde, data de 24 de agosto de 1945 e sua aprovação somente ocorre após quase 30 anos, depois de muitas perdas e desvios de vários outros anteprojetos, posteriores ao de 1945. Finalmente, em 12 de julho de 1973, foi sancionada a Lei 5.905/73 que "dispõe sobre a criação dos Conselhos Federal e Regionais de Enfermagem e dá outras providências". Este foi vinculado ao Ministério do Trabalho sob portaria no 3059, publicada em 5 de março de 1975. Na ocasião, assumiu o Conselho Federal de Enfermagem (COFEN), na condição de primeira presidente, Maria Rosa Souza Pinheiro ${ }^{(1)}$.

Mesmo antes da criação do Conselho, a ABEn trabalhou para aprovar seu primeiro código de ética, após realizar três congressos brasileiros, tendo a ética como tema oficial.

Todos esses feitos e iniciativas representaram um grande esforço dos profissionais de enfermagem, através de suas lideranças e, sem dúvida, a Associação teve um peso decisivo como o lócus por excelência desta organização. No entanto, apesar de seu trabalho constante e combativo em prol da edificação da profissão e da conquista de espaços profissionais, a ABEn, nos seus primeiros 50 anos de existência, voltou-se essencialmente para os interesses internos da enfermagem. Nesse sentido, no campo da legislação alcançou várias conquistas, tendo na figura expressiva da professora Haydée Guanaes Dourado seu maior expoente.

Não obstante, a entidade acenou muito pouco para as lutas da sociedade civil como um todo e para a área da saúde, em particular, embora o país tenha vivido momentos de muita 
efervescência política, por exemplo o período que antecede ao golpe civil-militar, início da década de 1960.

Mas como a história não se processa de forma linear, mesmo ao longo desses 50 anos ecoaram vozes discordantes no interior da enfermagem, porém sem força suficiente para abrir novos debates que apontassem em direção às questões sociais afligindo a população brasileira e redundando em sérios problemas de saúde.

No entanto, ao processo de redemocratização do país, iniciado na década de 1980, antecederam-se vários movimentos que, aos poucos, foram se organizando desde os anos de 1970, dentre os quais o movimento sanitário brasileiro que congregou um grande número de profissionais da saúde e das ciências sociais. Mesmo que ainda timidamente, a enfermagem brasileira se integra às lutas sociais como um todo e, particularmente, ao debate empreendido em função da reforma sanitária. Por outro lado, no âmbito interno da profissão, surgem novos debates motivados, em parte, pelo processo de abertura política do país, em pleno curso, mas também a partir da produção de trabalhos acadêmicos oriundos dos programas de pós-graduação em enfermagem e áreas afins que começaram a se estruturar, também nos anos 1980 do século XX. Uma parcela dessa produção tratou de resgatar a história da enfermagem brasileira, elaborando análises críticas sobre a profissão e a formação de seus profissionais, a essa altura considerando os três níveis - auxiliar, técnico e enfermeiro -, o processo de trabalho da enfermagem e, sobretudo, as posições políticas das entidades representativas da categoria. Foi, portanto, no próprio interior da $A B E n$ que se travou um longo e profundo debate em torno da renovação da profissão, dando origem ao chamado Movimento Participação, com base em um outro paradigma, o da visão crítica da realidade social, estimulando a efetiva participação dos associados. Sobre este movimento é importante referenciar a dissertação de mestrado em Ciências Sociais, defendida, na UFRN, pela professora Francisca Valda da Silva, em 1990.

Torna-se oportuno assinalarqueainda na década anterior,início dos anos 1980, a ABEn e o COFEN com a colaboração da OPAS, Ministério da Saúde e secretarias estaduais de saúde, realizaram uma pesquisa, em todo o território nacional, sobre a força de trabalho da enfermagem, a exemplo do levantamento dos anos 1950. Para tanto contaram com outras condições materiais e de infraestrutura, que possibilitaram um trabalho amplo e de peso, em um curto espaço de tempo. Os pesquisadores responsáveis por esse estudo, em cada unidade da federação, participaram de um curso preparatório, no Rio de janeiro, para, posteriormente, em um prazo preestabelecido, realizarem a coleta de dados. Isso possibilitou a publicação de um relatório, em dois tomos, que trouxe inúmeras contribuições à formação e ao exercício profissional da enfermagem, tais como: identificação do quantitativo dos recursos humanos; a forma como este vinha sendo distribuído; a capacitação de seus profissionais; as áreas mais deficitárias, entre outras informações importantes. Cabe salientar que na fase preparatória da pesquisa ocorreram muitas discussões acerca da formação profissional em seus diferentes níveis, bem como da posição política da enfermagem frente ao contexto da saúde e do próprio movimento sanitário, em franca ascensão naquele momento. Nota-se, portanto, uma tendência para a abertura política da profissão que irá fortalecer, logo em seguida, a campanha que desaguaria numa nova iniciativa nas fileiras da enfermagem.

\section{Democratização interna, interlocução com a sociedade}

O Movimento Participação surge e ganha corpo nos primeiros anos da década de 1980, envolvendo um grande número de profissionais oriundos, em sua maioria, de outros movimentos sociais e partidos políticos de oposição ao regime militar, que eclodiam no contexto histórico desse período. Teve "o intuito de criar uma nova visão sobre a profissão de enfermagem, em que os agentes produtores de serviços de saúde não sejam alienados do processo de produção do serviço e, muito menos de seu envolvimento com a ação política, necessária à transformação da sociedade"(3).

Nessa perspectiva, buscou a adesão dos estudantes de enfermagem, através de suas entidades representativas, e tratou de se expandir, ampliando o debate entre os profissionais por ocasião dos congressos e outros eventos menores da categoria, mas, sobretudo, trabalhando no sentido de renovar as $A B E n s$ estaduais com vistas a assumir a $A B E n$ nacional. Por conseguinte, ante os esforços empreendidos, e a grande militância para as eleições de 1984, o Movimento Participação teve sua chapa vitoriosa, cuja presidente seria a professora Maria José dos Santos Rossi. Porém, o pleito foi anulado pela diretoria em exercício, dirigida pela professora Circe de Melo Ribeiro, com o apoio de um grupo de congressistas. A Associação celebrava naquela ocasião o XXXVI Congresso Brasileiro de Enfermagem, realizado em Minas Gerais, na cidade de Belo Horizonte.

Esse episódio revoltou uma parcela significativa dos sócios da entidade e de estudantes que protestaram de forma veemente, contrários, portanto, à posição autoritária assumida pela diretoria da ABEn. Com isso, o grupo ganhou cada vez mais força, o que se confirmaria na eleição seguinte, ocorrida em 1986, com uma esmagadora vitória do Movimento Participação. A primeira presidência dessa nova fase coube à professora Maria José dos Santos Rossi. Tratou a nova diretoria de transformar a ABEn em uma entidade, de fato, representativa dos anseios da enfermagem brasileira, em defesa das causas coletivas da saúde e da enfermagem. No campo da formação, concedia pleno e irrestrito apoio à comissão de educação que, nessa fase, realizou um amplo debate em torno de um projeto político/pedagógico para o 
curso de enfermagem, envolvendo todas as escolas e cursos de enfermagem, da esfera pública. Tinha em sua pauta a defesa dos princípios defendidos pela reforma sanitária brasileira e, ao mesmo tempo, a observância das diretrizes que vinham sendo discutidas na nova Lei de Diretrizes e Bases da Educação Nacional, em vias de aprovação.

Mas a nova gestão não somente se empenhou em relação ao projeto educacional. As inserções políticas dessa e de outras diretorias que se sucederam, apoiadas pelo Movimento Participação, mantiveram uma interlocução com os movimentos sociais, ganhando maior visibilidade e propiciando um clima mais democrático no encaminhamento de suas diversas lutas. A título de exemplo, deve ser lembrado o movimento contra o ato médico junto aos demais profissionais da saúde, a jornada de 30 horas semanais de trabalho, a defesa em prol da reforma sanitária, entre tantas outras reivindicações.

Até esse período, final dos anos 1980, a organização da enfermagem brasileira, em parte, resultava daquilo que defendia o conjunto de suas entidades, em que pesem as divergências de encaminhamento político existentes entre a ABEn, Sistema COFEN/CORENs e Sindicatos de Enfermagem, o que seria previsível. O Brasil vivia um momento de transição democrática e de muitos embates entre as diferentes tendências políticas que se apresentavam e com as quais, naturalmente, a enfermagem também se enfrentava e convivia.

Neste contexto foi criado o Fórum Nacional de Entidades de Enfermagem, com o propósito de discutir sobre problemas inerentes à profissão, às políticas públicas para a área da saúde e, de modo particular, contribuir com a discussão acerca do Sistema Único de Saúde (SUS), em fase de implantação, garantida no texto da Constituição Federal de 1988. Além disso, o fórum tinha como princípio encaminhar lutas conjuntas fortalecendo a dimensão política da categoria.

\section{Tolerância e determinação}

No início da década de 1990, a nova diretoria do COFEN, sob a coordenação do enfermeiro Gilberto Linhares mudou os rumos dessa parceria existente entre as entidades de enfermagem, contribuindo para o desaparecimento progressivo do fórum. Essa diretoria contava com um grupo de apoio que, pelas evidências, tinha a pretensão de se perpetuar na autarquia. Muitas críticas foram exercidas, nessa nova fase, sobre a direção do COFEN, porém sem força para mudar sua política corporativista e particularista, além de autoritária e repressora.

No entanto, a insatisfação da grande maioria dos enfermeiros e mesmo as denúncias em relação à política implementada pelo Conselho, com supostas práticas de improbidade administrativa, contribuíram para o surgimento de uma vertente do Movimento Participação, o Movimento Nacional pela Moralização e Inovação do Sistema COFEN/CORENs, conhecido por Movimentação. Em sua agenda política, criou, em 1997, o “Dia Nacional de Luta pela Moralização e Inovação no Sistema COFEN/CORENs" e, alguns anos mais tarde, por proposição do Conselho Nacional da ABEn (CONABEN), o "Dia Nacional de Lutas contra a Impunidade", como parte da programação da Semana Brasileira de Enfermagem ${ }^{(4)}$. Todas essas iniciativas contribuíram para uma maior politização de enfermeiros e estudantes de enfermagem, na luta por um Conselho representativo dos ideais da enfermagem brasileira.

A luta desenvolvida pelo "Movimentação" que se espalhou por quase todos os estados brasileiros, fortaleceu o grupo que fazia oposição às políticas do Conselho, da forma como vinham sendo processadas. Finalmente rendeu frutos na medida em que as denúncias tiveram eco na área judicial, culminando, no ano de 2005, com a prisão de membros da diretoria, entre os quais Gilberto Linhares, o principal articulador político.

Em meio a toda essa turbulência, e diante da perplexidade de muitos enfermeiros, pois não há notícias de algo semelhante na história da enfermagem brasileira, eis que surge uma nova fase na relação entre as entidades. A constituição provisória de outra diretoria do Conselho, sob a presidência de Manuel Carlos Neri da Silva, abriu horizontes na medida em que buscou o diálogo com lideranças da $A B E n$ e com outras referências da enfermagem. Essa posição, um tanto corajosa, pelo fato de não contar com o apoio integral de sua própria diretoria, possibilitou a redefinição de novas políticas e atitudes de reaproximação com a $A B E n$, o que sinaliza para o encaminhamento futuro de algumas lutas conjuntas.

De todo modo, deve-se reconhecer que, embora não se possa afirmar que houve uma ruptura com a cultura instalada, a partir de um grupo político que permaneceu por 16 anos na direção do Conselho, é possível identificar uma agenda de entendimentos ABEn/COFEN e evidências de uma quebra de hegemonia(4).

Portanto, a organização da enfermagem brasileira, que ocorre por meio de suas entidades representativas, passa, atualmente, por um processo de transição e exige de seus dirigentes, mas também do conjunto dos profissionais, tolerância e determinação, além de uma participação efetiva nos seus fóruns de debate, com vistas ao fortalecimento da profissão.

\section{Referências}

1. Germano RM. Educação e ideologia da enfermagem no Brasil. 4a ed.

São Caetano do Sul: Yendis; 2007.

2. Carvalho AC. Associação Brasileira de Enfermagem: 1926-1976.

Documentário. Brasília: ABEn; 1976.

3. Albuquerque GL. A luta pela identidade profissional profissional:

participação e enfermagem. Florianópolis: UFSC; 2002.

4. Anotaçōes do COREN/RN. Rio Grande do Norte: COREN/RN; 2010. 